\title{
CRESCIMENTO DE Bradyrhizobium elkanii ESTIRPE BR 29 EM MEIOS DE CULTIVO COM DIFERENTES VALORES DE pH INICIAL $^{1}$
}

\author{
Growth of Bradyrhizobium elkanii Strain BR 29 in culture media with different pH values
}

\author{
Alexandre Barberi ${ }^{2}$, Fátima M. S. Moreira ${ }^{3}$ Ligiane Aparecida Florentino $^{4}$, Maria Isabel D. Rodrigues ${ }^{5}$
}

\section{RESUMO}

A soja, atualmente, é a leguminosa de maior expressão econômica no Brasil. Em razão da demanda crescente no mercado internacional, a cultura encontra-se em larga expansão em todo território brasileiro. Em alguns ensaios realizados em solos ácidos brasileiros, sob sistema de plantio direto, essa cultura tem mostrado baixa resposta à aplicação de calcário. Porém, a acidez é um dos fatores que limitam a eficiência da simbiose rizóbio-leguminosas. Para contornar esses problemas, poderiam ser utilizadas estirpes tolerantes à acidez do solo ou induzir tolerância nas estirpes já utilizadas. Em alguns trabalhos, tem-se demonstrado indução de tolerância à acidez quando a bactéria é previamente exposta a pH ácido. Assim, objetivou-se com este trabalho verificar o crescimento de Bradyrhizobium elkanii estirpe $\mathrm{Br} 29$ em meios de cultura sob diferentes condições de $\mathrm{pH}$ inicial. Foram realizados dois experimentos com dois meios de cultivo diferentes, em que se variou o pH inicial $(6,8 ; 6,0 ; 5,5)$. Foram avaliados: o crescimento da estirpe, pela contagem do número de unidades formadoras de colônia (UFC) e por densidade ótica, assim como as mudanças do $\mathrm{pH}$ nos meios. As curvas de crescimento obtidas variaram de acordo com o pH inicial e com a composição do meio de cultura. Com base no número máximo de UFC.mL ${ }^{-1}$, para o meio Lorda \& Balatti modificado, o melhor $\mathrm{pH}$ foi 6,0 e, no meio Lopreto, o melhor $\mathrm{pH}$ foi 5,5. O melhor crescimento em $\mathrm{pH}$ mais baixo $(5,5)$ está associado à maior produção de exopolissacarídeo.

Termos para indexação: Rizóbio, acidez, tempo de geração, unidades formadoras de colônia, densidade ótica.

\begin{abstract}
Currently soybean is the most economically important legume crop in Brazil. Due to its profitability soybean is being widely spread out all over the national territory. Some assays have shown low response of this crop to liming in acid Brazilian soil, under no-till age systems. Acidity is one of the factors that limit the efficiency of the symbiosis rhizobia - legumes. This problem could be solved if acid tolerant strains were obtained or if tolerance to acidity could be induced. Some papers demonstrated induced tolerance to acidity when the bacterium is previously exposed to a slightly acid $\mathrm{pH}$. The aim of this study was to verify the growth of Bradyrhizobium elkanii strain $\mathrm{Br} 29$ in culture media with different $\mathrm{pH}$ values $(6.8 ; 6.0$; 5.5). Two experiments were carried out with two different culture media varying mainly regarding initial $\mathrm{pH}$. Strain growth, by optical density and colony forming units (CFU) number, and $\mathrm{pH}$ medium modification were evaluated. Growth curves varied either in accordance with $\mathrm{pH}$ or culture media composition. Growth based on maximum number of CFU.mL ${ }^{-1}$ was better at $\mathrm{pH} 5.5$ in Lopreto medium and at $\mathrm{pH} 6.0$ at Lorda and Balatti medium. Better growth on lowest $\mathrm{pH}$ (5.5) was related to greater exopolyssacaride production.
\end{abstract}

Index terms: Rhizobia, acidity, generation time, colony forming units, optical density.

(Recebido para publicação em 9 de junho de 2003 e aprovado em 26 de agosto de 2003)

\section{INTRODUÇÃO}

Atualmente a soja (Glycine max (L.) Merril) é a leguminosa de maior importância na pauta de exportação do Brasil. A sua expansão ocorreu nos anos 70, devido ao interesse crescente da indústria de óleo e à demanda do mercado internacional. Assim, na safra
2002/2003, a área plantada de soja no Brasil foi de 18 milhões de hectares, alcançando uma produção de 52,5 milhões de toneladas (CONAB, 2003), colocando o Brasil como maior exportador mundial. A soja brasileira somente conseguiu chegar a esses patamares graças ao preço competitivo no mercado internacional. Avanços no melhoramento genético da planta e nas pes-

\footnotetext{
1. Parte da dissertação apresentada àUniversidade Federal de Lavras/UFLA, Caixa Postal 37-37200-000 - Lavras, MG, pelo primeiro autor, como um dos requisitos do Curso de Mestrado em Agronomia, área de concentração Solos e Nutrição de Plantas. Apoio financeiro CNPq.

2. Engenheiro Agrônomo, M.Sc., Doutorando, Departamento de Ciência do Solos/UFLA, Bolsista da CAPES, barberi@ufla.br.

3. Engenheiro Agrônomo, Ph.D., Professora Adjunta, Departamento de Ciência do Solo/UFLA, Bolsista do CNPq, fmoreira@ufla.br.

4. Aluna de graduação em Engenharia Agronômica/UFLA, bolsista de iniciação científica do CNPq.

5. Aluna de graduação em Engenharia Florestal/UFLA, bolsista de iniciação científica do CNPq.
} 
quisas em microbiologia do solo tornaram possíveis substituir a adubação nitrogenada pelo uso de inoculantes com estirpes de Bradyrhizobium japonicum e Bradyrhizobium elkanii Isso proporcionou um suprimento de quase todo nitrogênio demandado pela cultura, equivalente a mais de $250 \mathrm{~kg}$ de N.ha ${ }^{-1}$ por cultivo (URQUIAGA et al., 1999), o que representa uma economia para o Pais equivalente a 1,4 bilhão de dólares.

Para garantir os benefícios proporcionados pela fixação biológica de nitrogênio (FBN), o agricultor necessita introduzir, por meio da inoculação, uma população adequada de estirpes de bactérias eficientes na fixação do nitrogênio, alcançando, assim, uma alta eficiência da FBN.

Cultivando-se soja em sistema de plantio direto em solos ácidos brasileiros, alguns pesquisadores, como Caires et al. (1998, 1999), Pöttker e Ben (1998) e Moreira (1999), têm verificado a baixa resposta dessa cultura à correção da acidez do solo, alcançando boas produtividades mesmo em solos naturalmente ácidos. Um dos fatores que podem determinar a baixa resposta da soja à calagem em solos de cerrado é a deficiência natural desses solos em micronutrientes, como cobre, zinco e manganês, que têm sua disponibilidade reduzida com o aumento do $\mathrm{pH}$.

Com isso, torna-se importante a seleção de bactérias fixadoras de nitrogênio (BFN) mais adaptadas a índices mais elevados de acidez ou adaptação das estirpes de BFN já utilizadas nos inoculantes a essa nova faixa de pH. Em alguns trabalhos tem sido demonstrados melhor adaptação de bactérias à acidez quando previamente crescidas em meios de cultura levemente ácidos, fenômeno conhecido como "acid habituation" (GOODSON e ROWBURY, 1989a, 1989b) ou "adaptative tolerance response" (FOSTER e HALL, 1990, 1991; DILWORTH et al., 1999; O'HARA et al., 1989). Essas observações aumentam os questionamentos sobre as condições de cultivo apropriadas para a preparação de inoculantes para solos ácidos, pois bactérias crescidas em $\mathrm{pH}$ 5,0 podem ter maior chance de sobreviver em solos ácidos do que aquelas crescidas em $\mathrm{pH} 7,0$ (O'HARA e GLENN, 1989). Miguel e Moreira (2001) verificaram maior produção de exopolissacarídeos e de número de unidades formadoras de colônias por estirpes de Bradyrhizobium ( $\mathrm{Br} 29, \mathrm{Br}$ 4406, SEMIA 587 e INPA 401-11B) crescidas em meio de cultura extrato de levedura (yeast) e manitol (YM) (VINCENT, 1970) com pH inicial igual a 6,0, em comparação com os outros tratamentos $(\mathrm{pH}$ inicial 5,0 e 6,8).
Com este trabalho objetivou-se avaliar o crescimento da estirpe Br 29 (= SEMIA 5019 = Br 29w) de Bradyrhizobium elkanii em dois meios de cultura (LOPRETO, 1972, citado por URENHA et al., 1994; LORDA e BALATTI, 1996), sob diferentes condições de $\mathrm{pH}$ inicial $(5,5 ; 6,0$ e 6,8$)$.

\section{MATERIAL E MÉTODOS}

Foram conduzidos dois experimentos no Setor de Microbiologia do Solo do Departamento de Ciências do Solo da UFLA com a estirpe Br 29 (= SEMIA $5019=\mathrm{Br} 29 \mathrm{w}$ ), que pertence à espécie Bradyrhizobium elkanii e foi isolada na Embrapa Agrobiologia. Essa é utilizada como inoculante desde 1979, sendo considerada competitiva em solos de Cerrado (PERES e VIDOR, 1980).

\section{Experimento I: Influência do pH inicial do meio de cultura e do cálcio na produção de cé- lulas de rizóbio}

Este experimento foi conduzido em um delineamento inteiramente casualizado em um esquema fatorial (4 tratamentos por 9 épocas de avaliação) com 4 repetições. O meio utilizado foi o de Lopreto (1972), citado por Urenha et al. (1994) (composição por litro: $10 \mathrm{~g}$ de Glicerol; $4 \mathrm{~g}$ de Extrato de levedura; $0,5 \mathrm{~g}$ de $\mathrm{K}_{2} \mathrm{HPO}_{4}$; $0,2 \mathrm{~g}$ de $\mathrm{MgSO}_{4} 7 \mathrm{H}_{2} \mathrm{O} ; 0,1 \mathrm{~g}$ de $\mathrm{NaCl} ; 0,8 \mathrm{~g}$ de $\mathrm{KNO}_{3}$; $0,3 \mathrm{~g}$ de $\left(\mathrm{NH}_{4}\right)_{2} \mathrm{HPO}_{4} ; 2$ gotas de $\mathrm{MnSO}_{4} 10 \% ; 2$ gotas de $\mathrm{FeCl}_{3}$ a $10 \%$ ), adicionado de $1 \mathrm{~mL}$ de solução de micronutrientes de Zabriskie, descrita por Urenha et al. (1994), (composição por litro: $0,22 \mathrm{~g}$ de $\mathrm{ZnSO}_{4} \cdot 7 \mathrm{H}_{2} \mathrm{O}$; $0,55 \mathrm{~g}$ de $\mathrm{CaCl}_{2} ; 0,50 \mathrm{~g}$ de $\mathrm{MnCl}_{2} ; 0,50 \mathrm{~g}$ de $0,10 \mathrm{~g}$ de $\mathrm{FeSO}_{4} ;\left(\mathrm{NH}_{4}\right)_{6} \mathrm{Mo}_{7} \mathrm{O}_{24} \cdot 4 \mathrm{H}_{2} \mathrm{O} ; 0,16 \mathrm{~g}$ de $\mathrm{CuSO}_{4}$ e $0,16 \mathrm{~g}$ de $\mathrm{CoCl}_{2}$ ). Distribuíram-se $150 \mathrm{~mL}$ do meio citado acima em erlenmeyers de $250 \mathrm{~mL}$. Após autoclavagem dos erlenmeyers a $121^{\circ} \mathrm{C}$ por 20 minutos e resfriamento à temperatura ambiente, procedeu-se à inoculação deles com colônias da estirpe $\mathrm{Br} 29$ com o auxílio de uma alça de platina. Essas colônias foram obtidas depois de crescidas por 7 dias em placa de Petri com meio 79 (FRED e WAKSMAN, 1928) (composição por litro: $10 \mathrm{~g}$ de Manitol; $0,4 \mathrm{~g}$ de Extrato de levedura; $1 \mathrm{ml}$ de $\mathrm{K}_{2} \mathrm{HPO}_{4}$ a $10 \%$; $4 \mathrm{ml}$ de $\mathrm{KH}_{2} \mathrm{PO}_{4}$ a $10 \% ; 2 \mathrm{ml}$ de $\mathrm{Mg}$ $\mathrm{SO}_{4} 7 \mathrm{H}_{2} \mathrm{O}$ a $10 \% ; 1 \mathrm{ml}$ de $\mathrm{NaCl}$ a $10 \% ; 5 \mathrm{ml}$ de Azul de Bromothimol a $0,5 \%$ em $\mathrm{KOH}$ a $0,2 \mathrm{~N} ; 15 \mathrm{~g}$ de agar).

Os tratamentos testados foram: meio com $\mathrm{pH}$ inicial 5,5; meio com $\mathrm{pH}$ inicial 5,5 mais 0,5 g.L. ${ }^{-1}$ de cloreto de cálcio; meio com pH inicial 6,0 e meio com $\mathrm{pH}$ inicial 6,8. O pH do meio foi ajustado para $\mathrm{pH} 5,5$;

Ciênc. agrotec., Lavras, v. 28, n. 2, p. 397-405, mar./abr., 2004 
6,0 e 6,8 com solução de $\mathrm{HCl} 2 \mathrm{~N}$, somente antes da autoclavagem.

Após a inoculação, os erlenmeyers foram mantidos sob agitação constante, em um agitador orbital, a $110 \mathrm{rpm}$ por 216 horas a $28^{\circ} \mathrm{C}$. A cada 24 horas, foram retiradas alíquotas de $1 \mathrm{~mL}$ para contagem de unidades formadoras de colônia (UFC. $\mathrm{mL}^{-1}$ ) em placa, pelo método da inoculação de gotas proposto por Miles e Misra (1938).

Para a contagem de UFC. $\mathrm{mL}^{-1}$, foi retirado $1 \mathrm{~mL}$ de caldo de cada erlenmeyer, colocando-se em um tubo de ensaio contendo $9 \mathrm{~mL}$ de solução fisiológica $(\mathrm{NaCl}$ $0,55 \%)$, previamente autoclavado. Agitou-se por $10 \mathrm{se}-$ gundos em vórtex, originando uma solução com concentração de diluição $10^{-1}$. Posteriormente, retirou-se 1 $\mathrm{mL}$ da solução $10^{-1}$, o qual foi colocado em outro tubo com 9 mL de solução, seguindo o procedimento citado acima, originando a diluição $10^{-2}$. Esse processo foi realizado sucessivamente até a obtenção da diluição $10^{-9}$. Em seguida, foram retiradas alíquotas de $0,02 \mathrm{~mL}$ das diluições $10^{-4}, 10^{-5}, 10^{-6}, 10^{-7}, 10^{-8}$ e $10^{-9}$, as quais foram colocadas em placas de Petri contendo meio 79 e divididas previamente em seis setores, utilizando-se um setor da placa por diluição. Esse procedimento foi realizado em número de três repetições. Após a inoculação e secagem da alíquota à temperatura ambiente, as placas foram colocadas invertidas em uma câmara de crescimento a $28^{\circ} \mathrm{C}$ pelo período de 7 dias, quando, então, foi efetuada a contagem das UFC da diluição, que apresentou de 6 a 50 UFC por gota de $0,02 \mathrm{~mL}$, seguindo procedimentos de Miles e Misra (1938). Dessas diluições, foram retiradas as médias ponderadas das contagens das três repetições e, a partir desses valores de UFC, foram construídas curvas de crescimento em função do tempo. Para a obtenção do tempo de geração, dividiu-se um intervalo de tempo especifico $\left(\Delta \mathrm{T}_{2}-\mathrm{T}_{1}\right)$ em horas (na fase log) pelo número de gerações. Esse foi calculado pelo logaritmo na base 2 da divisão das UFC. $\mathrm{mL}^{-1}$ em $\mathrm{T}_{2}$ pelas UFC.mL $\mathrm{mL}^{-1}$ em .

\section{Experimento II: Influência do pH inicial e do tamponamento do meio de cultura na produ- ção de células de rizóbio}

Este experimento foi conduzido em um delineamento inteiramente casualizado em esquema fatorial (3 tratamentos por 7 épocas de avaliação) com 4 repetições. O meio utilizado neste experimento teve como base o meio Lorda e Balatti (1996) (composição por litro: $10 \mathrm{~g}$ de Glicerol; $4 \mathrm{~g}$ de Extrato de levedura; 0,2 $\mathrm{g}$ de
$\mathrm{MgSO}_{4} 7 \mathrm{H}_{2} \mathrm{O} ; 0,1 \mathrm{~g}$ de $\mathrm{NaCl} ; 0,8 \mathrm{~g}$ de $\mathrm{KNO}_{3} ; 0,3 \mathrm{~g}$ de $\left(\mathrm{NH}_{4}\right)_{2} \mathrm{PO}_{4}$ substituído por $0,3 \mathrm{~g}$ de $\left(\mathrm{NH}_{4}\right)_{2} \mathrm{SO}_{4} ; 0,06 \mathrm{~mL}$ de $\mathrm{MnSO}_{4}$ a $10 \%$ e $0,06 \mathrm{~mL}$ de $\mathrm{FeCl}_{3}$ a $10 \%$ ). Os tratamentos testados foram diferentes valores iniciais de $\mathrm{pH}(5,5,6,0$ e 6,8). Todos os três tratamentos receberam as mesmas quantidades de compostos utilizados no meio, só diferindo na proporção de íons de fosfato utilizados para o tamponamento desejado. Para isso, foram utilizadas duas soluções a $8,81 \mathrm{mM}$ de concentração de $\mathrm{K}_{2} \mathrm{HPO}_{4}(\mathrm{k} 2)$ e $\mathrm{KH}_{2} \mathrm{PO}_{4}(\mathrm{k} 1)$, colocados nas seguintes proporções: $55 \mathrm{~mL} \mathrm{k2}+45 \mathrm{~mL} \mathrm{k} 1$ para $\mathrm{pH} 6,8 ; 20 \mathrm{~mL}$ $\mathrm{k} 2+80 \mathrm{~mL} \mathrm{k} 1$ para $\mathrm{pH}$ 6,0 e $4 \mathrm{~mL}$ k $2+96 \mathrm{~mL} \mathrm{k} 1$ para $\mathrm{pH}$ 5,5 em um volume de um litro.

Para a padronização do inóculo inicial, uma colônia isolada após crescimento da estirpe por 7 dias em meio 79 foi inoculada em meio Lorda e Balatti (1996) com $\mathrm{pH} 6,8$; ficando sob agitação por seis dias. Em seguida, uma alíquota de $1 \mathrm{~mL}$ foi inoculada em erlenmeyers de $250 \mathrm{~mL}$ contendo $149 \mathrm{~mL}$ do respectivo meio, com valores de $\mathrm{pH}$ ajustado para $5.5,6.0$ e 6.8 , com solução de $\mathrm{HCl} 2 \mathrm{~N}$ com 4 repetições por tratamento.

Após a inoculação, os erlenmeyers foram mantidos sob agitação constante em um agitador orbital, a $110 \mathrm{rpm}$ por 168 horas a $28^{\circ} \mathrm{C}$. A cada 24 horas, foram retiradas alíquotas de $1 \mathrm{~mL}$ para a contagem de UFC.mL $L^{-1}$, que foi realizada como no experimento 1 . Alíquotas de $5 \mathrm{~mL}$ foram retiradas para determinação de densidade ótica e do valor de $\mathrm{pH}$. Para a avaliação da densidade ótica, foi utilizado um espectrofotômetro marca Hitachi, modelo U-2001 UV/Vis, fazendo-se a leitura da absorbância a $560 \mathrm{~nm}$ e utilizando como padrão "0" água destilada, sendo utilizadas as leituras realizadas somente na fase log de crescimento, intervalo de 0 a 48 h, para a diminuição dos efeitos de possíveis células mortas. Para leitura de $\mathrm{pH}$, utilizou-se de um potenciômetro previamente calibrado.

A densidade ótica expressa o número de células mais os exopolissacarídeos (EPS) produzidos por essas células. A produção de EPS é uma resposta de várias espécies de bactérias a uma gama de fatores limitantes, EPS pode ter um papel integral por permitir que um organismo sobreviva sob uma variedade de circunstâncias estressantes (CUNNINGHAM e MUNNS, 1984).

Para avaliar a produção de EPS, utilizaram-se as equações de regressão da densidade ótica em função ao log de UFC. $\mathrm{mL}^{-1}$, tomando-se um mesmo número base de $10^{8,8}$ UFC. $\mathrm{mL}^{-1}$ para permitir a comparação das diferenças na densidade ótica nos três tratamentos. 
Todos os dados foram analisados no programa estatístico SISVAR, versão 4.3 (FERREIRA, 2000). As médias dos tratamentos foram comparadas pelo teste de Tukey a $5 \%$ de probabilidade.

\section{RESULTADOS E DISCUSSÃO}

Experimento I: Influência do pH inicial e do cálcio do meio de cultura na produção de células de rizóbio

Na Figura 1 são apresentadas as curvas de crescimento em meio de cultura Lopreto (1972), citado por Urenha et al. (1994), para os quatro tratamentos. Houve crescimento satisfatório da estirpe de Bradyrhizobium elkanii $\mathrm{Br} 29$ em todos os tratamentos. No entanto, os tratamentos diferiram significativamente quanto à curva de crescimento.

A comparação das médias de $\log$ UFC. $\mathrm{mL}^{-1}$ (Tabela 1) revelou que os tratamentos com $\mathrm{pH}$ inicial 6,8 e 5,5+Ca foram os que apresentaram o maior número médio geral de UFC. $\mathrm{mL}^{-1}$ e o tratamento com $\mathrm{pH}$ inicial 6,0 foi o que teve o menor. No entanto, os valores de número máximo de UFC. $\mathrm{mL}^{-1}$ obtidos a partir das equações das curvas de crescimento mostraram que os tratamentos com $\mathrm{pH}$ inicial 6,8;6,0 e 5,5+Ca, não diferiram, sendo o tratamento com $\mathrm{pH}$ inicial 5,5 o que apresentou maior número máximo de células.
TABELA 1 - Médias do $\log$ de UFC.mL $L^{-1}$ em relação ao tempo (h) e número máximo (NM) de UFC. $\mathrm{mL}^{-1}$ obtidos a partir das curvas de crescimento para os quatro tratamentos de $\mathrm{pH}$ inicial do meio.

\begin{tabular}{|c|c|c|c|c|c|}
\hline \multirow[t]{2}{*}{ Tempo } & \multicolumn{4}{|c|}{ Tratamentos } & \multirow[t]{2}{*}{ Geral } \\
\hline & 6,8 & 6 & 5,5 & $5,5+\mathrm{Ca}$ & \\
\hline 24 & $6,8 \mathrm{a}$ & $6,08 \mathrm{a}$ & $6,33 a$ & $6,57 \mathrm{a}$ & $6,45 \mathrm{D}$ \\
\hline 48 & $7,01 \mathrm{a}$ & $5,95 \mathrm{a}$ & $6,28 \mathrm{a}$ & $6,68 \mathrm{a}$ & $6,48 \mathrm{D}$ \\
\hline 72 & $8,06 a$ & $6,63 b$ & $6,75 b$ & $7,22 \mathrm{ab}$ & $7,16 \mathrm{C}$ \\
\hline 96 & $9,03 a$ & $7,76 b$ & $8,11 \mathrm{ab}$ & $8,38 \mathrm{ab}$ & $8,32 \mathrm{~B}$ \\
\hline 120 & $9,6 \mathrm{a}$ & $8,88 \mathrm{a}$ & $9,12 \mathrm{a}$ & $9,06 \mathrm{a}$ & $9,16 \mathrm{~A}$ \\
\hline 144 & $9,73 a$ & $9,25 \mathrm{a}$ & $9,26 \mathrm{a}$ & $9,42 \mathrm{a}$ & $9,68 \mathrm{~A}$ \\
\hline 168 & $9,59 a$ & $9,12 \mathrm{a}$ & $9,54 \mathrm{a}$ & $9,67 \mathrm{a}$ & $9,48 \mathrm{~A}$ \\
\hline 192 & $9,85 \mathrm{a}$ & $9,34 \mathrm{a}$ & $9,94 \mathrm{a}$ & $9,76 \mathrm{a}$ & $9,73 \mathrm{~A}$ \\
\hline 216 & $9,23 \mathrm{a}$ & $9,27 \mathrm{a}$ & $9,86 a$ & $9,6 \mathrm{a}$ & $9,49 \mathrm{~A}$ \\
\hline Geral & $8,76 a$ & $8,03 \mathrm{c}$ & $8,36 \mathrm{bc}$ & $8,61 \mathrm{ab}$ & 8,44 \\
\hline NM & $9,74 b$ & $9,42 b$ & $10,19 \mathrm{a}$ & $9,76 b$ & \\
\hline
\end{tabular}

Médias seguidas da mesma letra minúscula, na horizontal, e maiúscula, na vertical, não diferem entre si pelo teste de Tukey a $5 \%$.

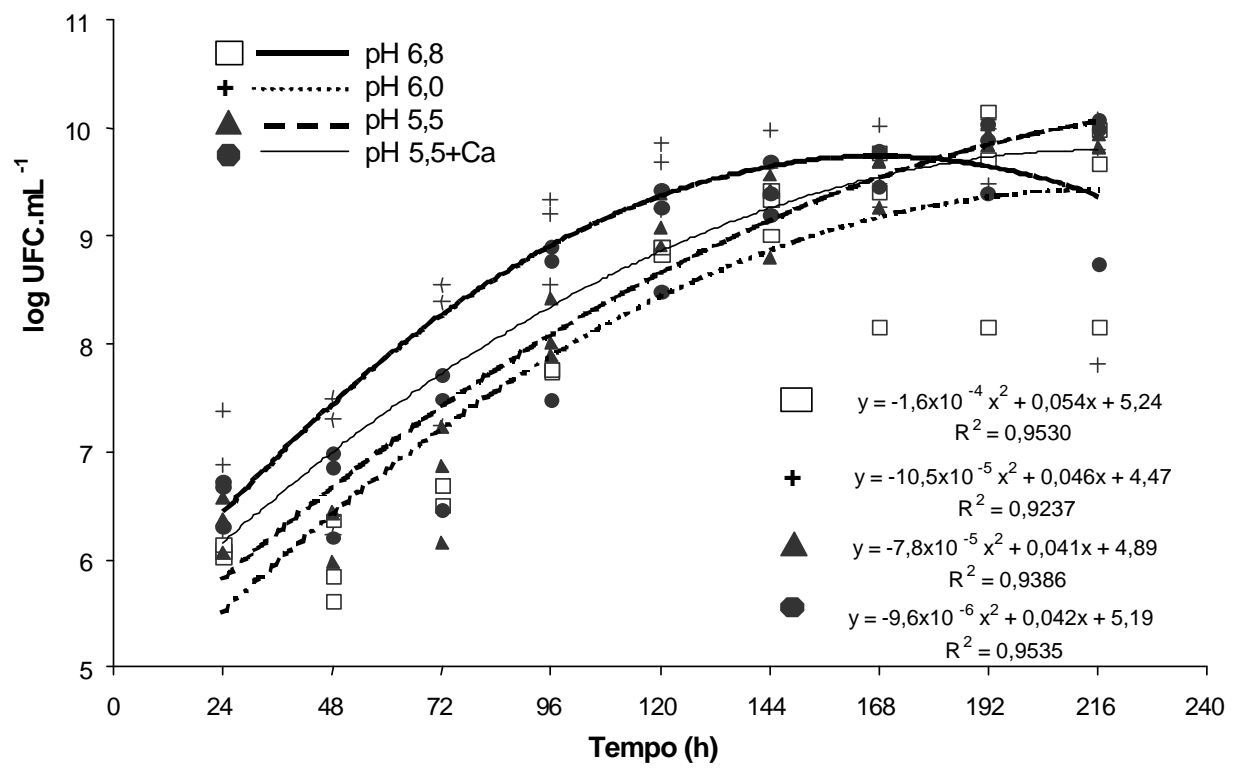

FIGURA 1 - Curvas de crescimento de Bradyrhizobium elkanii (Br 29) em meio de cultura Lopreto (1972), citado por Urenha et al. (1994), sob diferentes condições de pH inicial.

Ciênc. agrotec., Lavras, v. 28, n. 2, p. 397-405, mar./abr., 2004 
O tempo aproximado necessário para que os tratamentos $(6,8 ; 6,0 ; 5,5$ e 5,5+Ca) alcançassem o número máximo de UFC.mL ${ }^{-1}$ foram, respectivamente, 168 , 217,261 e 218 horas.

A contagem das UFC. $\mathrm{mL}^{-1}$ para as primeiras 24 horas mostrou grande amplitude de valores entre as repetições (Figura 1), e a não-padronização do inóculo inicial pode ter causado essa diferença, já que algumas repetições podem ter sido inoculadas com maior ou menor número de células.

Não ocorreu diferença para o parâmetro tempo de geração no intervalo entre 24 horas e 120 horas, sendo o valor médio desse, para os quatro tratamentos, de 10,807 horas. Esse valor confirma valores encontrados por Kennedy e Greenwood (1982), citados por Moreira (1991), para tempo de geração de estirpes de crescimento lento, que foram maiores ou iguais a 8,5 horas.

\section{Experimento II: Influência do pH inicial e do tamponamento do meio de cultura na produ- ção de células de rizóbio}

Verificou-se um aumento progressivo do $\mathrm{pH}$ do meio em decorrência da multiplicação das células ao longo do tempo (Figura 2), sendo mais acentuado nos tratamentos com valores de $\mathrm{pH}$ inicial 5,5 e 6,0; confirmando resultados obtidos por Ribeiro Júnior et al. (1987). Entretanto, após 72 horas, não havia mais diferença estatística entre o $\mathrm{pH}$ dos tratamentos, de modo que se pode concluir que o $\mathrm{pH}$ inicial do meio pouco in- fluencia o crescimento bacteriano após esse período. Alguns autores relatam a ocorrência do fenômeno de "acid habituation" (GOODSON e ROWBURY, 1989a, 1989b) ou "adaptative tolerance response" (FOSTER e HALL, 1990, 1991; DILWORTH et al., 1999; O’HARA et al., 1989), mas, vários pesquisadores (BROMFIELD e JONES, 1980; HOWIESON et al., 1992; GEMELL e ROUGHLEY, 1993) encontraram baixa correlação entre estirpes tolerantes a $\mathrm{pH}$ ácido em meio de cultura e tolerância à acidez do solo. Esses resultados poderiam ser explicados pela facilidade de alteração do $\mathrm{pH}$ do meio, devido ao seu baixo poder tampão em relação à grande concentração de UFC.mL ${ }^{-1}$ existente no meio. Em contrapartida, no solo, e também na rizosfera, o poder tampão é bem maior, e o número de UFC.g ${ }^{-1}$, bem menor.

Assim, a capacidade de alteração do meio poderia ser de menor importância do que outros mecanismos adotados pelos microorganismos para se protegerem dos efeitos deletérios do íon hidrogênio e de outros íons associados à condição de acidez elevada. Por outro lado, os microrganismos se nutrem com compostos utilizados para tamponamento do meio, neutralizando seus efeitos.

Em função da padronização do inóculo inicial, verificou-se uma diminuição da amplitude do crescimento do rizóbio (Figura 3) em relação ao experimento 1, sem padronização. Isso possibilitou a diminuição do coeficiente de variação encontrado nas análises de variância dos dois experimentos, os quais foram de $7,5 \%$ no experimento 1 e de $0,82 \%$ no experimento 2 , aumentando a confiabilidade dos resultados.

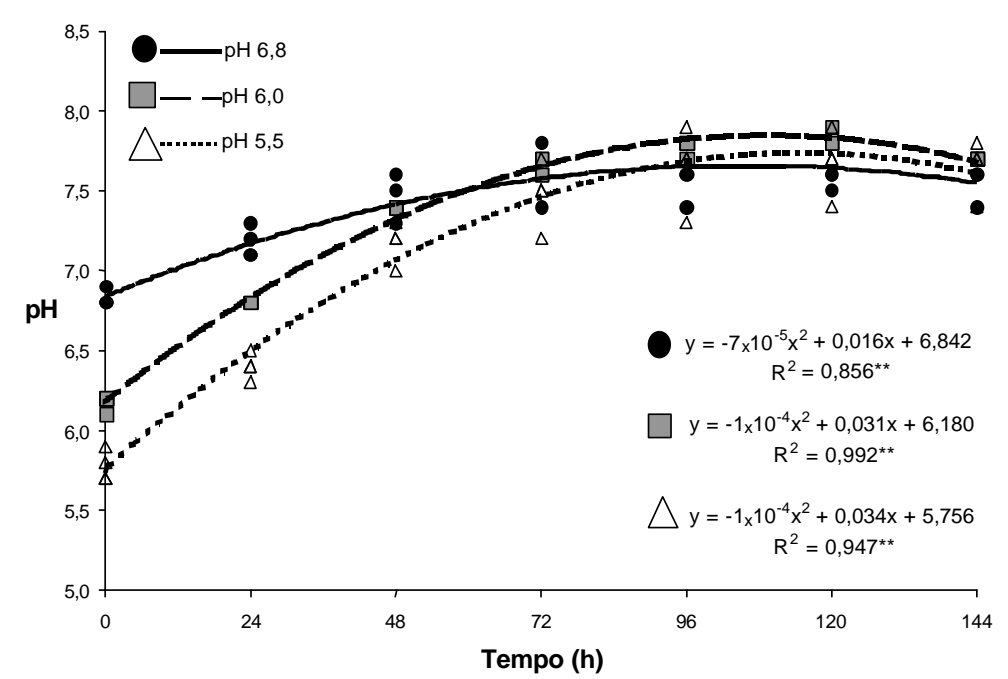

FIGURA 2 - Evolução do pH do meio de cultura (LORDA e BALATTI, 1996) em relação a diferentes condições de $\mathrm{pH}$ inicial. 


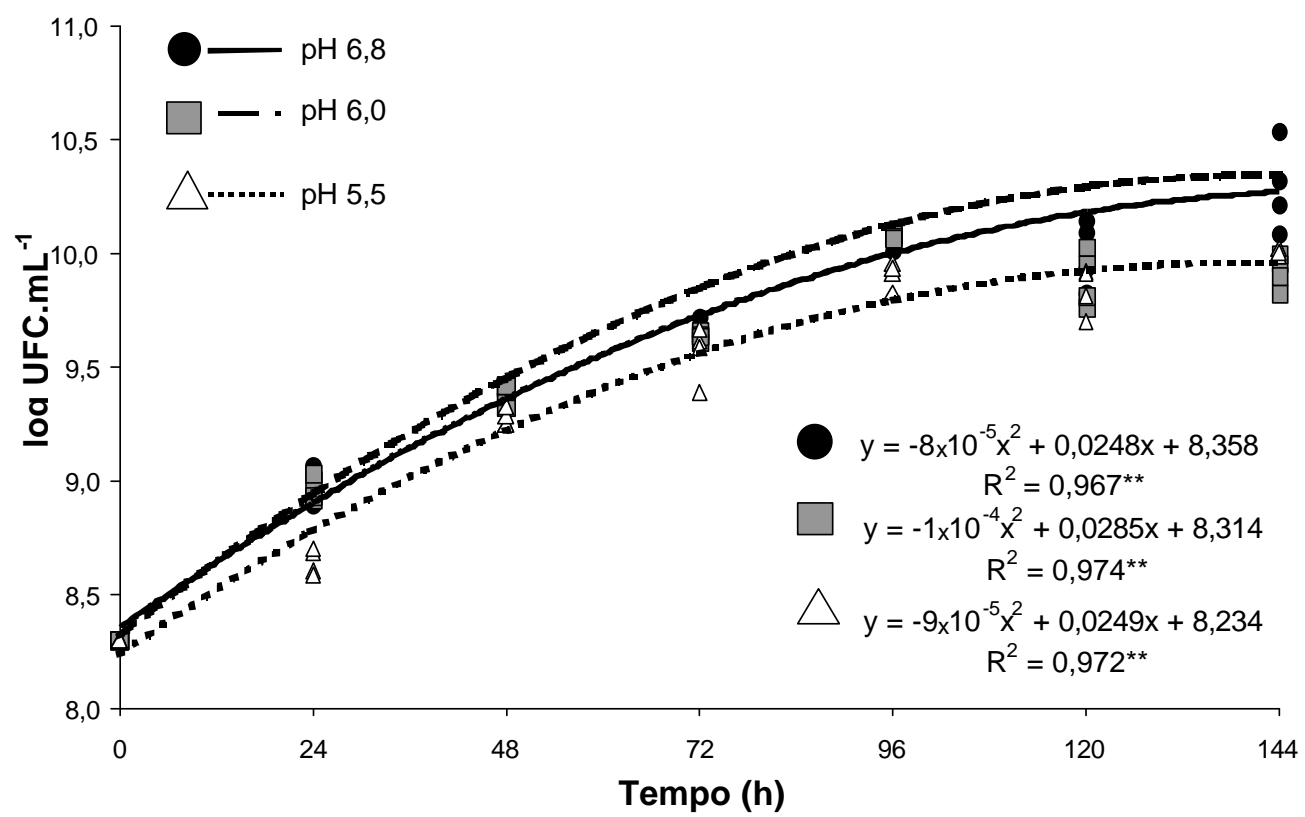

FIGURA 3 - Curvas de crescimento de Bradyrhizobium elkanii ( $\mathrm{Br} 29$ ) para os tratamentos com pH inicial do meio (LORDA e BALATTI, 1996) tamponado a 6,8; 6,0 e 5,5.

Ocorreu significância pela análise de variância $(p \leq 0,01)$ para os parâmetros: tratamentos, tempo e sua interação, assim como para o tempo de geração no intervalo de 0 a 96 horas. Houve um aumento do tempo de geração para o tratamento com $\mathrm{pH}$ inicial de 5,5, que foi de 18,081 horas, diferindo dos outros tratamentos; para os tratamentos com $\mathrm{pH}$ inicial de 6,8 e 6,0, os tempos de geração foram de 16,577 horas e 16,321 horas, respectivamente, não diferindo entre si pelo teste de Tukey a 5\%. Esses valores foram diferentes dos encontrados no primeiro experimento, provavelmente devido a diferente composição dos meios. Esse valor confirma resultados encontrados por Kennedy e Greenwood (1982), citados por Moreira (1991), para estirpes de crescimento lento.

Na tabela 2 são apresentadas as médias de log dos números de UFC.mL ${ }^{-1}$, sendo esses superiores aos encontrados por Miguel e Moreira (2001), que foram aproximadamente $10^{9}$. Isso é explicado pela melhor utilização da fonte de carbono do meio Lorda e Balatti (1996), que em sua composição possui glicerol, em comparação com o manitol utilizado no meio YM (VINCENT, 1970) utilizado por esses autores.

A partir das equações das curvas de crescimento, foi obtido o $\log$ do número máximo de UFC. $\mathrm{mL}^{-1}$ para cada tratamento, os quais foram comparados pelo teste de Tukey a 5\% (Tabela 2), verificando-se que o tratamento com $\mathrm{pH}$ inicial 6,0 obteve o maior número máximo, seguido pelo tratamento com $\mathrm{pH}$ inicial de 6,8, e pelo tratamento com $\mathrm{pH}$ inicial 5,5. Esses valores confirmam resultados obtidos por Miguel e Moreira (2001), que também obtiveram o maior número máximo de UFC. $\mathrm{mL}^{-1}$ no tratamento com pH igual a 6,0. No entanto, o tempo para atingir o crescimento máximo, obtido também pelas equações das curvas de crescimento, para os tratamentos com $\mathrm{pH}$ inicial 6,8; 6,0 e 5,5 foi respectivamente 155,143 e 138 horas, diferindo dos resultados obtidos por Miguel e Moreira (2001), que encontraram respectivamente 165,143 e 159 horas para os tratamentos com valores de $\mathrm{pH}$ de 6,8, 6,0 e 5,0 . Isso também pode ser explicado pela diferença na composição dos meios, principalmente pela fonte de carbono e pelo fato de o número de células inoculadas ter sido maior no presente experimento.

Para o parâmetro densidade ótica do meio de cultura, em decorrência do tempo, para os três tratamentos com pH inicial do meio de 6,8; 6,0 e 5,5, ocorreu significância estatística. Verificou-se alta correlação entre $\log$ UFC. $\mathrm{mL}^{-1}$ e densidade ótica, encontrando pela análise de correlação um valor de $81 \%$ para todos os três tratamentos juntos (Figura 4). 


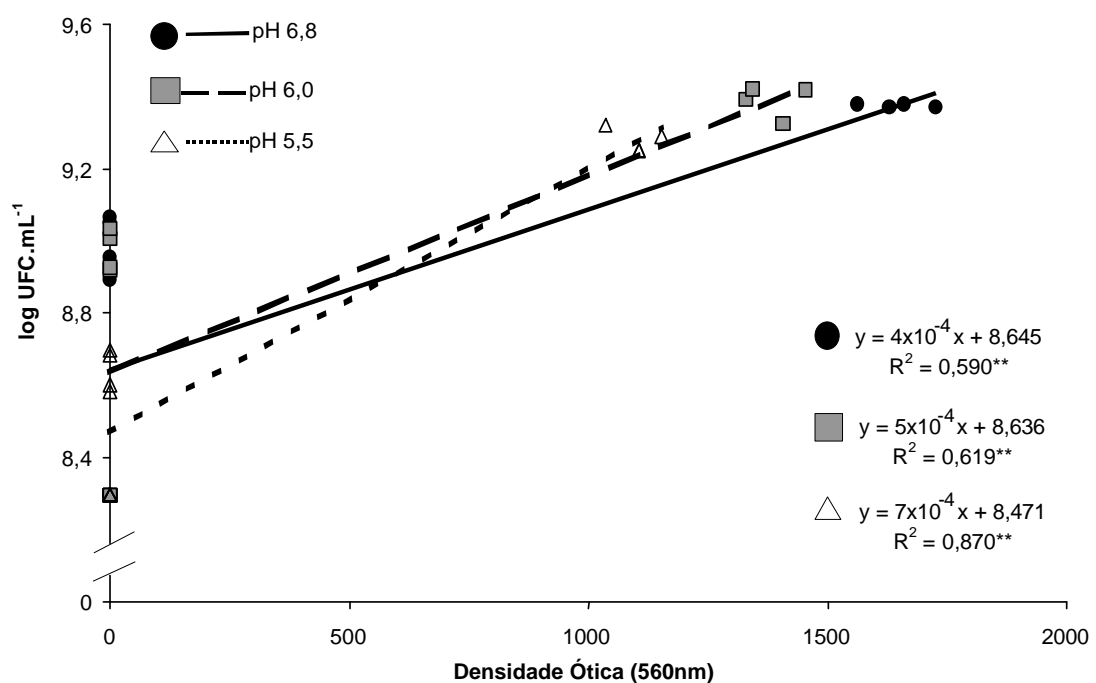

FIGURA 4 - Evolução da densidade ótica em relação ao log UFC.mL $L^{-1}$ para os três tratamentos com pH inicial do meio igual a 6,$8 ; 6,0$ e 5,5 .

TABELA 2 - Médias do $\log$ de UFC.mL $L^{-1}$ em relação ao tempo (h) e log do número máximo de UFC.mL $L^{-1}$ (NM), para os três tratamentos, $\mathrm{pH}$ inicial do meio tamponado 6,8; 6,0 e 5,5.

\begin{tabular}{ccccc}
\hline \multirow{2}{*}{$\begin{array}{c}\text { Tempo } \\
\text { (h) }\end{array}$} & \multicolumn{3}{c}{ Tratamentos } & Geral \\
\cline { 2 - 4 } & $\mathbf{6 , 8}$ & $\mathbf{6 , 0}$ & $\mathbf{5 , 5}$ & \\
\hline 0 & $8,30 \mathrm{a}$ & $8,30 \mathrm{a}$ & $8,30 \mathrm{a}$ & $8,30 \mathrm{~F}$ \\
24 & $8,99 \mathrm{a}$ & $8,97 \mathrm{a}$ & $8,64 \mathrm{~b}$ & $8,87 \mathrm{E}$ \\
48 & $9,66 \mathrm{a}$ & $9,64 \mathrm{a}$ & $9,56 \mathrm{a}$ & $9,35 \mathrm{D}$ \\
72 & $9,37 \mathrm{a}$ & $9,39 \mathrm{a}$ & $9,28 \mathrm{a}$ & $9,62 \mathrm{C}$ \\
96 & $10,05 \mathrm{a}$ & $10,08 \mathrm{a}$ & $9,91 \mathrm{~b}$ & $10,01 \mathrm{~A}$ \\
120 & $9,99 \mathrm{a}$ & $9,89 \mathrm{ab}$ & $9,84 \mathrm{~b}$ & $9,91 \mathrm{~B}$ \\
144 & $10,29 \mathrm{a}$ & $9,92 \mathrm{~b}$ & $10,00 \mathrm{~b}$ & $10,07 \mathrm{~A}$ \\
\hline Geral & $9,52 \mathrm{a}$ & $9,45 \mathrm{~b}$ & $9,36 \mathrm{c}$ & 9,45 \\
\hline NM & $10,28 \mathrm{~b}$ & $10,34 \mathrm{a}$ & $9,96 \mathrm{c}$ & \\
\hline
\end{tabular}

Médias seguidas da mesma letra minúscula, na vertical, e maiúscula, na horizontal, não diferem entre si pelo teste de Tukey a $5 \%$.

Verificou-se que, na concentração de $10^{8,8}$ UFC. $\mathrm{mL}^{-1}$, as densidades óticas dos tratamentos com $\mathrm{pH}$ inicial 6,8; 6,0 e 5,5 foram, respectivamente,
0,$386 ; 0,328$ e 0,470 , indicando, portanto produção crescente de EPS em pH 5,5, 6,8 e 6,0. Miguel e Moreira (2001), utilizando meio YM, obtiveram maior densidade ótica para o tratamento com $\mathrm{pH}$ igual a 6,0 do que no $\mathrm{pH} \mathrm{6,8,} \mathrm{utilizando} \mathrm{o} \mathrm{mesmo}$ número-base $\left(10^{8,8} \mathrm{UFC}\right.$. $\left.\mathrm{mL}^{-1}\right)$, o que provavelmente está relacionado com a diferente composição dos meio, principalmente com relação à fonte de carbono. Cunningham e Munns (1984), em meio YMA (modificado por KEYSER e MUNNS, 1979), obtiveram maior quantidade de EPS em estirpes de Rhizobium tolerantes à acidez do meio, quando expostas a meio ácido. Com esses resultados, demonstra-se que uma maior produção de exopolissacarídeos pode estar associada como resposta aos efeitos deletérios da acidez.

\section{CONCLUSÕES}

a) $\mathrm{O} \mathrm{pH}$ inicial do meio influenciou o crescimento da estirpe estudada. Porém, as respostas aos diferentes valores de $\mathrm{pH}$ variaram de acordo com o meio de cultura utilizado;

b) Com base no número máximo de UFC.mL $\mathrm{m}^{-1}$ para o meio Lorda e Balatti (1996), o melhor $\mathrm{pH}$ foi 6,0 e, no meio Lopreto, o melhor $\mathrm{pH}$ foi 5,5;

c) $\mathrm{O}$ crescimento em $\mathrm{pH}$ mais baixo $(5,5)$ está associado à maior produção de exopolissacarídeo. 


\section{REFERÊNCIAS BIBLIOGRÁFICAS}

BROMFIELD, E. S. P.; JONES, D. G. Studies on acid tolerance of Rhizobium trifolii in culture and soil. Journal Applied Bacteriology, Washington, v. 48, n. 3, p. 243-264, Mar. 1980.

CAIRES, E. F.; CHUEIRI, W. A.; MADRUGA, E. F.; FIGUEIREDO, A. Alterações de características químicas do solo e resposta da soja ao calcário e gesso aplicados na superfície em sistema de cultivo sem preparo do solo. Revista Brasileira de Ciência do Solo, Viçosa, v. 22, n. 1, p. 27-34, jan./mar. 1998.

CAIRES, E. F.; FONSECA, A. F.; MENDES, J.; CHUEIRI, W. A.; MADRUGA, E. F. Produção de milho, trigo e soja em função das alterações das características químicas do solo pela aplicação de calcário e gesso na superfície, em sistema de plantio direto. Revista Brasileira de Ciência do Solo, Viçosa, v. 23, n. 2, p. 315-327, abr./jun. 1999.

CONAB, 2003. Disponível em: <http://www.conab.gov. br>. Acesso em: 10 dez. 2003.

CUNNINGHAM, S. D.; MUNNS, D. N. Effects of rhizobial extracellular polysaccharide on $\mathrm{pH}$ and aluminum activity. Soil Science Society American Journal, Madison, v. 48, n. 6, p. 1276-1280, Nov./Dec. 1984.

DILWORTH, M. J.; RYNNE, F. G.; CASTELLI; VIVAS-MARFISI, A. I.; GLENN, A. R. Survival and exopolysaccharide production in Sinorhizobium meliloti WSM419 are affected by calcium and low $\mathrm{pH}$. Microbiology, Reading, v. 145, n. 7, p. 1585-1593, July 1999.

FERREIRA, D. F. Análises estatísticas por meio do SISVAR para Windows: versão 4.0. In: REUNIÃO ANUAL DA REGIÃO BRASILEIRO DA SOCIEDADE INTERNACIONAL DE BIOMETRIA, 45., 2000, São Carlos. Anais... São Carlos: UFSCAR, 2000 .

FOSTER, J. W.; HALL, H. K. Adaptive acidification tolerance response of Salmonella typhimurium. Journal of Bacteriology, Washington, v. 172, n. 2, p. 771-778, Feb. 1990
FOSTER, J. W.; HALL, H. K. Inducible $\mathrm{pH}$ homeostasis and the acid tolerance response of $S$. typhimurium. Journal of Bacteriology, Washington, v. 173, n. 16, p. 5129-5135, Aug. 1991.

FRED, E. B.; WAKSMAN, S. A. Laboratory manual of general microbiology. New York: McGraw-Hill Book, 1928. 143 p.

GEMELL, L. G.; ROUGHLEY, R. J. Field evaluation in acid soils of strains of Rhizobium leguminosarum bv trifolii selected for their tolerance or sensitivity to acid soil factors in agar medium. Soil Biology and Biochemistry, Oxford, v. 25, n. 10, p. 1447-1452, Oct. 1993.

GOODSON, M.; ROWBURY, R. J. Habituation to normally lethal acidity by prior growth Escherichia coli at a sub lethal acid $\mathrm{pH}$ value. Letters in Applied Microbiology, Oxford, v. 8, n. 1, p. 77-79, 1989a.

GOODSON, M.; ROWBURY, R. J. Resistance of acid-habituation Escherichia coli to organic acids and its medical and applied significance. Letters in Applied Microbiology, Oxford, v. 8, n. 6, p. 211214, 1989b.

HOWIESON, J. G.; ROBSON, A. D.; ABBOTT, L. K. Acid tolerant species of Medicago produce root exudates at low $\mathrm{pH}$ which induce the expression of nodulation genes in Rhizobium meliloti. Australian Journal Plant Physiology, Murdoch, v. 19, n. 3, p. 287-296, 1992.

KEYSER, H. H.; MUNNS, D. N. Tolerence of Rhizobia to acidity, aluminum and phosphate. Soil Science Society American Journal, Madison, v. 43, n. 3, p. 519-523, May/June 1979.

LORDA, G. S.; BALATTI, A. P. Designing média I. In: BALLATI, A. P.; FREIRE, J. R. J. Legume inoculants: selection and characterization of strains: production, use and management. New York: [s.n.], 1996.

MIGUEL, D. L.; MOREIRA, F. M. S. Influencia do pH do meio de cultivo e da turfa no comportamento de estirpes de Bradyrhizobium. Revista Brasileira de Ciência do Solo, Viçosa, v. 25, n. 4, p. 873-883, out./dez. 2001. 
MILES, A. A.; MISRA, S. S. The estimations of the bactericidal power of the blood. Journal of Hygiene, Cambridge, v. 38, n. 6, p. 732-749, 1938.

MOREIRA, F. M. S. Caracterização de estirpes de rizóbio isoladas de espécies florestais pertencentes a diversos grupos de divergência de leguminosas introduzidas ou nativas da Amazônia e Mata Atlântica. 1991.160 f. Tese (Doutorado em Solos) - Universidade Federal do Rio de Janeiro, Itajaí, 1991.

MOREIRA, S. G. Calagem em sistema de semeadura direta e efeitos sobre a acidez do solo, disponibilidade de nutrientes e produção de soja. Piracicaba: ESALQ/USP, 1999. 87 p.

O'HARA, G. W.; GLENN, A. R. The adaptive acid tolerance response in root nodule bacteria and Escherichia coli. Archives of Microbiology, New York, v. 161, n. 4, p. 286-292, Apr. 1989.

O'HARA, G. W.; GOSS, T. J.; DILWORTH, M. J.; GLENN, A. R. Maintenance of intracellular $\mathrm{pH}$ and acid tolerance in Rhizobium meliloti. Applied and Environment Microbiology, Washington, v. 55, n. 8, p. 1870-1876, Aug. 1989.

PERES, J. R. R.; VIDOR, C. Relação entre concentração de células no inoculante e competição por sítios de in- fecção nodular entre estirpes de Rhizobium japonicum em soja. Revista Brasileira de Ciência de Solo, Campinas, v. 4, n. 2, p. 139-143, maio/ago. 1980.

PÖTTKER, D.; BEN, J. R. Calagem para uma rotação de culturas no sistema plantio direto. Revista Brasileira de Ciência do Solo, Viçosa, v. 22, n. 4, p. 675-684, out./dez. 1998.

RIBEIRO JÚNIOR, W. Q.; FRANCO, A. A.; LOPES, E. S. Eficiência de estirpes de Bradyrhizobium spp., para quatro leguminosas arbóreas e competividade das estirpes em Albizia Lebbek em latossolo acído. Revista Brasileira de Ciência de Solo, Campinas, v. 11, n. 2, p. 275-282, maio/ago. 1987.

URENHA, L. C.; PRADELLA, J. G. C.; OLIVEIRA, M. S.; BONOMI, A. Produção de biomassa celular de rizóbio. In: HUNGRIA, M.; ARAUJO, R. S. Manual de métodos empregados em estudos de microbiologia agrícola. Brasília: EMBRAPA-SPI, 1994. 542 p.

URQUIAGA, S.; BODDEY, R. M.; NEVES, M. C. P. $A$ necessidade de uma revolução mais verde: FERTBIO 1999, Lavras - MG. Lavras: UFLA, 1999.

VINCENT, J. M. A manual for the pratical study of the root nodule bacteria. Lodon: JBP, 1970. 164 p. 